\title{
On the Sustainable Development of Modern Sightseeing Agriculture Garden
}

\author{
Xiaoyu Wang \\ Huanghe Science and Technology College \\ Zhengzhou, China
}

\begin{abstract}
Sightseeing agriculture is an emerging industry in China. It is a recreational husbandry activity as well. Though it has long developed in abroad, it has begun in China before long. Agricultural sightseeing has brought great social, economic and ecological benefits and promoted diversified development of regional tourism. Based on the analysis and research of the problems exist in the plan of sightseeing agriculture garden, this paper has put forward some advices that helps its sustainable development and serves as reference for its design and construction.
\end{abstract}

Keywords-sightseeing agriculture garden; sustainable development; analysis

\section{INTRODUCTION}

In the stage of barbarism, people's survival was based on infant farming. Agricultural civilization has developed constantly in the long history of people's fighting with nature. Spiritual demand has been people's need from agriculture once again just like thousands of years ago. On this condition, sightseeing agriculture garden that is for eco-agricultural tourism has come into being.

As one of the main forms of ecotourism, sightseeing agriculture has its own advantages. Numbers of tourists have been attracted by its abundant resources, diversified forms and regional characteristics. In this way, sightseeing agriculture plays a vital role in improving the environment and developing tourist industry, economy and society. Sightseeing agriculture is different from agriculture and tourism respectively. It has features like sightseeing, effective agricultural production, improving ecoenvironment, living experience and promoting social culture. Sightseeing agriculture garden reflects people's innovation on mode of agricultural production, business operation and consumption pattern. It is a new thinking and pattern of modern agriculture with great prospect.

There is vigorous development of sightseeing agriculture garden. However in some well-developed areas, because of their bad planning and developed, they cannot expect its prosperous development. This paper has put forward suggestion on the design and construction of sightseeing agriculture garden with sustainable development.

\section{RElated CONCEPTS OF SightSEEING AgRicUlture}

\section{A. Agriculture}

A category of social production that makes agricultural products based on the vital functions of plants and animals by artificial cultivation. It includes farm production and animal husbandry. In tradition, there are five industries mainly. They are agriculture, forestry, animal husbandry, sideline occupation and fishery.

\section{B. Sightseeing}

As is stressed in The Book of Changes Guan, seeing the glorious sight of a country is sightseeing of a country. The definition of sightseeing by Ni Zhizhong is that people with certain wishes leave for a place with different sight of their own through a long trip during which they can enjoy everything in the environment.

\section{Sightseeing Agriculture}

Sightseeing agriculture also named tourism agriculture or recreational agriculture is the agriculture that deeply develops, improves and allocates the rural recourses according to the principal and features of modern agricultural tourism. It should perform the function of sightseeing, tasting, purchasing, entertainment, working, learning and living and perform the ecological function and protect the environment. At the same time, products with marketing function and rural (agricultural) features should be produced. In this way, a new type of agriculture with the combination of primary industry and tertiary industry and the unification of production and consumption can be shaped.

\section{Features of Modern Sightseeing Agriculture GARDEN}

The organic combination of agriculture and tourism makes the modern sightseeing agriculture gardens have features of both. The development of this industry is based on modern management on agricultural production. Its industrial planning follows the need of tourist market. The cross-permeation of agriculture and tourism results in the interactivity and additivity of agricultural performance and management efficiency. Ecological landscape is the recourse of the development of this industry. 


\section{A. Seasonal Characteristic of Sightseeing Agriculture}

Because of the habit of crops and the Seasonal limitation on outdoor activities, there exist obvious seasonality and periodicity of related business on sightseeing agriculture gardens. With season changes, different sights can be seen in it and tourists can join in different activities as well.

\section{B. The Extensive Tourist Market of Sightseeing Agriculture Garden}

Because of the characteristics of its marketing, it can attract people of all ages. Everyone has the expectation to devote himself to land and nature and to come back to infant farming era. So many tourists choose to visit here with their families and friends in spare time to be relaxed and to develop good relationship.

\section{The Diversified Content of Sightseeing Agriculture Garden}

Due to different climate and land configuration, mode of agricultural production and the custom vary a lot. Thus, sightseeing agriculture gardens with different features come into being. There are various things tourists can do in them, such as dong farming activities, entertaining, exercising and shopping.

\section{Multiple Economic Benefits Brought by Sightseeing Agriculture Garden}

There are extensive sources of sightseeing agriculture gardens' fund. Not only can it earn money by developing agricultural tourism, it can make contribution in many other aspects. First, in these gardens, we can do scientific research and teaching. For example, we can cultivate new cultivar; make them as experimental fields and carry out students' practicing, training and visiting there. At the same time, agricultural production and wholesale and retail of these products can be done there. They can serve as new ways to promote new agricultural products. Financial diversification of sightseeing agriculture garden can be seen from things above. In this way, multiple economic benefits can help cost recovering of the investors.

\section{PRoBlems on the DeVElopMENT OF SightSEeING AGRICULTURE GARDEN}

\section{A. On the Lack of Guidance on Regional Planning and the Disordered Development of Management}

Because of the high input with low output situation of traditional agriculture, the sightseeing agriculture enjoys rapid development. However, scientific designing based on the main target of some ecological gardens haven't been made; rich recourses haven't been made full use. Thus, there is no proper distribution of region and no appropriate design of tourist route. What's worse, structure of products is too single. Even though there are gardens managed by the thought of ecological balance of nature, they are not successful because administers are in weak literal quality and ecological knowledge.

\section{B. On the Lack of Clear Orientation; Overall Similarity and Weakening Sightseeing Function}

At present, the planning of these gardens has not been based on the repeatedly investigation and analysis of their local industrial advantages; finding out the characteristics of local traditional culture and natural resources and exact orientation of garden's development. On the contrary, they just build them by following the paces of these in foreign countries or the original scenic spots. Countless villas and entertainment places are built and holiday villages are developed in where there is with good climate. All these make it not eco-agricultural tourism, while instead make it normal and disordered scenic spot. In the end, this kind of gardens will lose competitiveness and can't attract tourists at all.

\section{On the Lack of Making Full Use of Basic Natural Resources; Ecological Degradation}

Plan and construction of many sightseeing agricultural gardens is just the copy of scenic spots. Thus, many infrastructures and artificial landscape that belong to parks and scenic spots occur in the sightseeing agricultural gardens. The reserve of natural resources has been analyzed and the essence of idyllic scenery and sightseeing agriculture hasn't been embodied. To sole these problems, we should allocate recourses and produce in the mode of the ecological garden. Eco-agriculture should be the core of agricultural sightseeing, which can help reflect the features of "overall, circulatory, coordinated and renewable" and the meaning of "ecoculture".

\section{On the Lack of Intensive Analysis of Its Location; Fewer Customers}

The site selection of sightseeing agricultural garden is closely related to both its external conditions, including zone bit, traffic and customers and internal conditions, including natural resources, cultural resources and production basis. For those with inconvenient traffic conditions and distant zone bit will not develop well. If there isn't objective evaluation on the resource conditions, the planning of site selection will turn out to be a failure. These gardens will lose competitiveness later.

\section{E. On the Lack of Overall Development; Less Development of Agriculture}

Some of the gardens attach great importance to the planning of scenery and sightseeing, while concerning little about the integrated research and development of agricultural products and sustainable development of agricultural industry. Gardens of this kind have deviated from the original intention and can not promote rural industrial structure adjustment and the sustainable development of modern agriculture.

\section{F. On the Lack of Public Education; Incapable to Serve as Example}

At present, there is a huge market gap in public education of market culture. The public education can better serve 
sightseeing agriculture which is the new developing direction of modern agriculture. Environmental protection education and public education should be carried out to tourists and primary and high school students in these gardens by constructing agricultural museums and exhibition hall. Meanwhile, to meet the demand of China's agricultural development and its structural adjustment, these gardens can be the agricultural technology communication center, training base and practice base of higher vocational colleges' students. It can help foster the image of specific in tourism products and perform its public education function.

\section{THE Strategies For SUSTAINABLE DEVELOPMENT OF MODERN SIGHTSEEING AGRICULTURE GARDENS}

Based on the analyses above, in order to make sound development of sightseeing agriculture gardens in China, we need to think out strategies both in macro and micro way. On macro level, government should strengthen its effort on planning and guidance. According to the economic and social development of that region, the government should appoint experts to evaluate its need of sightseeing agriculture; make assessment on tourist resources in or around that area; make proper orientation of the goal and characteristics of its development and give suggestions on the construction of sightseeing agriculture gardens. Support policies and promotion measures should be carried out to make it possible for sightseeing agriculture to be in the framework of economic and social development in its region. On micro level, scientific planning and management should be made; examples should be made and experience must be summed up; the construction of technicians should be strengthened to build high tech environment and their cooperation with tourism departments and media should be strengthened to better promote their development.

\section{A. Guiding Principle for Sustainable Development}

1) Adjust measures to local conditions and make overall consideration. The planning of sightseeing agriculture gardens should be based on overall consideration of the resources of agricultural production. Measures should be adjusted to local conditions. Construction of infrastructure should be carried out, for example, traffic, water and electricity, room and board and holiday villages. Besides, the planning of these gardens should be in accordance with local culture and human landscape. Only in this way, can agricultural products and high-quality tourism products with local cultural and agricultural characteristics be produced to the public.

2) Make high-quality products and build good image. As there is no competitive product and further development can not be made, the agricultural production of these gardens should base on ecological agricultural model. At the same time, they should adopt measures of organic cultivation to produce green vegetable, which can help the ecological gardens better play their role and reflect the prospect of hightech agriculture as well. Furthermore, overall image that is green, safe and ecology can be formed.
3)Make overall plans to achieve the target of sustainable development. The construction of sightseeing agriculture gardens should make ecological theory as its guideline and adopt modern management mechanism with ecological principle, environmental technology, and biotechnology. Thus, an agricultural ecosystem with virtuous cycle can form. The economic benefits will be made by the coordination between modern agricultural organic cultivation model and the application of high-tech production technique. Social benefits will be made by their design and planning. With the integration of economic, ecological and social benefits, sustainable development can be made.

\section{B. Methods for Sustainable Planning of Modern Sightseeing Agriculture Gardens}

Sustainable planning of sightseeing agriculture gardens includes industrial development part with industrial development as its core and garden construction part with land utilization as its core.

Based on overall investigations and analyses, the evaluation system for the development of sightseeing agricultural development should be established and the proportion of every part in this system should be clarified. Quantitative researches on basic resources by analytic hierarchy process should be made. In this way, they can know people's need for these resources and provide basis for overall orientation, industrial development planning and their running model. In the end, research report for the sustainable development of sightseeing agriculture can be made. Then, based on the report, constructive planning such as land applying planning and systematic scenery planning can be made. Projection scheme in aspects like the function allocation, systematic construction of scenery and construction of infrastructure should be made as well.

\section{Prospect OF SightSEEING AgRiculture GARDENS}

Sightseeing agriculture industry which shows a very strong momentum of development is an emerging industry in agricultural development. Though the managers are incapable and government departments have not performed their functions well, they still enjoy good development prospect. First of all, China is a vast country with different kinds of climates and landforms and various agricultural resources. On this condition, it has formed the space for ecological landscapes' development. It is suitable for developing agricultural tourism as well. Secondly, there is quantity of customers brought by tourism industry which is developing fast. Therefore, as travel becomes a fashion today and with the impetus of the holiday economy, the number of citizens going traveling is increasing. Thus, there is great potential for consumption. Customers there will become more and more.

\section{CONCLUSION}

Agricultural sightseeing which is an emerging industry of tourism is the combination of agricultural production and modern tourism industry. It helps promote the economic and social development and the improvement of environment. 
Nowadays, the planning of China's sightseeing agriculture gardens is still in its primary stage. In this paper, the author has made research and analyses to promote their sustainable development, which are expected to be a reference for the development of sightseeing agriculture projects.

\section{REFERENCES}

[1] Bao Yin. 21st Century Sightseeing Agriculture Gardens in Ecoagricultural Model [J]. Journal of Henan Vocational technical Teachers College, 2002, 30(3): 68-70.

[2] Yan Lidong. Ecological Innovation for Economic Sustainable Development[M]. Beijing: China Environmental Science Press, 2002 : 78- 80.

[3] . Guo Huancheng, Lv Mingwei, Ren Guozhu. The Planning and Design of Agritourism Gardens $[\mathrm{M}]$. Beijing: China Building Industry Press, 2007.

[4] Lv Mingwei, Guo Huancheng. The Developing Experience of Agricultural Tourism and Leisure Industry in Taiwan[J]. Technology and Industry Across the Straits, 2006(6): 36- 38.

[5] Zheng Jianxiong, Guo Huancheng, Chen Tian. The Development of Agritourism and Rural Tourism [M]. Beijing: Press of China University of Mining \&Technology, 2005. 